\title{
Article \\ Effects of Expansive Additives on the Shrinkage Behavior of Coal Gangue Based Alkali Activated Materials
}

\author{
Xu Gao ${ }^{1,+}$, Chao Liu ${ }^{2,+}$, Zhonghe Shui ${ }^{2}$ and Rui Yu ${ }^{2, *}$ D \\ 1 School of Civil Engineering and Architecture, Wuhan University of Technology, Wuhan 430070, China; \\ x.gao@whut.edu.cn \\ 2 State Key Laboratory of Silicate Materials for Architectures, Wuhan University of Technology, \\ Wuhan 430070, China; liuchao524829282@163.com (C.L.); zhshui@whut.edu.cn (Z.S.) \\ * Correspondence: r.yu@whut.edu.cn \\ + Equivalent first authors.
}

Citation: Gao, X.; Liu, C.; Shui, Z.; Yu, R. Effects of Expansive Additives on the Shrinkage Behavior of Coal Gangue Based Alkali Activated Materials. Crystals 2021, 11, 816. https://doi.org/10.3390/cryst11070816

Academic Editor: José L. García

Received: 7 June 2021

Accepted: 8 July 2021

Published: 14 July 2021

Publisher's Note: MDPI stays neutral with regard to jurisdictional claims in published maps and institutional affiliations.

Copyright: (c) 2021 by the authors. Licensee MDPI, Basel, Switzerland. This article is an open access article distributed under the terms and conditions of the Creative Commons Attribution (CC BY) license (https:// creativecommons.org/licenses/by/ $4.0 /)$.

\begin{abstract}
The suitability of applying shrinkage reducing additives in alkali activated coal gangue-slag composites is discussed in this study. The effect of sulphoaluminate cement (SAC), high performance concrete expansion agent (HCSA) and U-type expansion agent (UEA) on the reaction process, shrinkage behavior, phase composition, microstructure and mechanical properties are evaluated. The results show that the addition of SAC slightly mitigates the early stage reaction process, while HCSA and UEA can either accelerate or inhibit the reaction depending on their dosage. The addition of SAC presents an ideal balance between drying shrinkage reduction and strength increment. As for HCSA and UEA, the shrinkage and mechanical properties are sensitive to their replacement level; excessive dosage would result in remarkable strength reduction and expansion. The specific surface area and average pore size of the hardened matrix are found to be closely related with shrinkage behavior. SAC addition introduces additional hydrotalcite phases within the reaction products, while HCSA and UEA mainly result in the formation of $\mathrm{CaCO}_{3}$ and $\mathrm{Ca}(\mathrm{OH})_{2}$. It is concluded that applying expansive additives can be an effective approach in reducing the drying shrinkage of alkali activated coal gangue-slag mixtures, while their type and dosage must be carefully handled.
\end{abstract}

Keywords: alkali activation; coal gangue-slag blends; drying shrinkage; microstructure; compressive strength

\section{Introduction}

Coal is one of the most abundant applicable energy resources for modern society on earth. As the major by-product of coal mining industry, coal gangue has become one of the largest industrial solid wastes in China [1,2]. The undisposed coal gangue in mainland China is around 7 billion tons, along with an annual discharge of 280 million tons [3]. The un-managed coal gangue usually has evident negative impacts on the environment and human health, such as land occupation, leaching of hazardous elements and emission of pollutant gases like $\mathrm{CO}_{x}, \mathrm{SO}_{x}$ and $\mathrm{NO}_{x}[4-6]$.

Reusing coal gangue as construction and building material has been widely studied in the past decades. It has been successfully applied in the production of lightweight aggregate, brick and as filling material for pavement and mining applications [7-9]. Coal gangue also presents the potential to be reused as a reactive material for high-end applications, namely as a supplementary cementitious material to partially replace cement. The major mineral component of coal gangue is kaolinite, which consists of a large fraction of $\mathrm{SiO}_{2}$ and $\mathrm{Al}_{2} \mathrm{O}_{3}$. When kaolinite is heated up to around $550-750{ }^{\circ} \mathrm{C}$, metakaolin is formed with amorphous $\mathrm{SiO}_{2}$ and $\mathrm{Al}_{2} \mathrm{O}_{3}$ phases, exhibiting pozzolanic reactivity [10,11]. However, one intrinsic drawback of using coal gangue in producing blended cement is its relatively low reactivity and its strength reduction, which limits its replacement level lower than $20 \%$ in 
most cases [12]. Therefore, it is of great significance to develop approaches regarding the effective reuse of coal gangue with excellent properties.

On the other hand, growing interests have been paid to the utilization of alkali activated materials (AAMs), because of their obviously lower environmental impacts and excellent performances compared to Portland cement [13]. Theoretically, this material can be produced by using any solid precursors that contain reactive calcium, silicate and aluminate, forming C-A-S-H and N-A-S-H type gels that are similar to the hydration products of Portland cement [14-18]. This technology allows the possibility of producing a construction material with coal gangue content up to $100 \%$, with desired mechanical properties.

However, it was frequently reported that the alkali activated materials either with or without coal gangue exhibit higher shrinkage than OPC [19-23]. Ma [24] investigated the drying shrinkage of alkali activated coal gangue-slag mixture, and an optimal shrinkage was observed in the mixture with a slag content of $50 \%$ and an activator modulus of 1.5 . The study of Collins showed that the drying shrinkage of alkali activated slag was three times higher than that of ordinary Portland cement [25]; it was suggested that the pores with diameter below $25 \mathrm{~nm}$ were responsible for the shrinkage of alkali activated materials [26]. Methods to reduce the shrinkage behavior have also been discussed, the incorporation of $6 \%$ gypsum by weight of the binder was reported to be effective in reducing the drying shrinkage of alkali activated slag, which is due to the appearance of ettringite [27]. Provis found that calcite can effectively reduce the drying shrinkage of low calcium based alkali activated materials, because a small amount of calcite dissolution is enough to release enough $\mathrm{Ca}^{2+}$, it has a significant effect on metakaolin based alkali activated materials [28]. The addition of $\mathrm{MgO}$ possesses an obvious effect on reducing the shrinkage of alkali activated high calcium binders, due to the reduced amount of reacted C-A-S-H gels and increased formation of crystalline hydrotalcite phase [29-31]. The addition of nano- $\mathrm{TiO}_{2}$ in alkali activated materials was also found to reduce the drying shrinkage [32]. Gypsum was found to be beneficial to reduce the drying shrinkage of high calcium fly ash based alkali activated materials, due to the formation of ettringite [33].

Although several shrinkage reducing strategies were suggested from previous studies, and expansive agents have shown the potential to mitigate the shrinkage of alkali activated material, it is still necessary to evaluate the suitability and influencing mechanisms of expansive additives on coal gangue based alkali activated materials. In this study, three types of commonly applied expansive agents in cementitious materials, namely sulphoaluminate cement (SAC), high performance concrete expansion agent (HCSA) and U-type expansion agent (UEA), are used as the potential mineral shrinkage reducer for alkali activated coal gangue-slag composites. Their effects on drying shrinkage, compressive strength, phase assemblage, and micro structure are identified, and their potential shrinkage reducing mechanisms are discussed.

\section{Experimental}

\subsection{Raw Materials}

The coal gangue (CG) was obtained from Anhui province, China, and it was calcined at $700{ }^{\circ} \mathrm{C}$ for $2 \mathrm{~h}$ prior to use. Grade $\mathrm{S} 95$ granulated blast furnace slag (GBFS) was used as the high calcium binder. A mixture of sodium hydroxide powder and industrial water glass $\left(28.5 \% \mathrm{SiO}_{2}, 10 \% \mathrm{Na}_{2} \mathrm{O}, 61.5 \% \mathrm{H}_{2} \mathrm{O}\right)$ were used as the alkali activator. Sulphoaluminate cement (SAC), high performance concrete expansion agent (HCSA) and U-type concrete expansion agent (UEA) were used as expansive additives. In addition, CEN standard sand was used as fine aggregates. The chemical compositions of applied powder materials are listed in Table 1.

\subsection{Mixture Proportions}

The mixture proportions used in this study are listed in Table 2. Fixed equivalent $\mathrm{Na}_{2} \mathrm{O}$ content of $8 \%$ (by weight of the binder), activator modulus of 1.6 , and water to binder ratio of 0.4 were used for all mixtures. The reference sample, labeled as "AACGS", 
was designed to have a calcined coal gangue to slag ratio of $40 / 60$ based on previous experiences of the authors, which would exhibit acceptable general properties regarding fluidity, setting time and mechanical properties. Expansive additives of SAC, HCSA and UEA were incorporated individually in the binding system to evaluate their potential effects on micro and macro properties, and three levels of additive replacements were applied, namely $3 \%, 5 \%$ and $7 \%$ by weight of the binder.

Table 1. Chemical composition of raw materials and additives (wt.\%).

\begin{tabular}{cccccccccccc}
\hline & $\mathbf{S i O}_{\mathbf{2}}$ & $\mathbf{A l}_{\mathbf{2}} \mathbf{O}_{\mathbf{3}}$ & $\mathbf{F e}_{\mathbf{2}} \mathbf{O}_{\mathbf{3}}$ & $\mathbf{C a O}$ & $\mathbf{M g O}$ & $\mathbf{S O}_{\mathbf{3}}$ & $\mathbf{K}_{\mathbf{2}} \mathbf{O}$ & $\mathbf{N a}_{\mathbf{2}} \mathbf{O}$ & $\mathbf{T i O}_{\mathbf{2}}$ & $\mathbf{S r O}$ & $\mathbf{L} . \mathbf{O} . \mathbf{I}$ \\
\hline C G & 53.11 & 26.43 & 2.88 & 0.77 & 0.44 & 0.52 & 0.34 & 0.34 & 0.79 & 0 & 13.14 \\
GBFS & 32.4 & 15.1 & 0.46 & 41.23 & 6.61 & 2.18 & 0.48 & 0.27 & 0.84 & 0 & 0.22 \\
SAC & 6.19 & 19.35 & 7.72 & 43.31 & 1.24 & 14.58 & 0.14 & 0.12 & 1.11 & 0.20 & 6.04 \\
HCSA & 2.89 & 3.40 & 0.76 & 68.89 & 2.11 & 18.76 & 0.26 & 0.05 & 0.15 & 0.26 & 2.47 \\
UEA & 5.33 & 2.35 & 0.74 & 71.59 & 4.18 & 10.38 & 0.31 & 0.05 & 0.14 & 0.13 & 4.80 \\
\hline
\end{tabular}

(L.O.I refers to loss on ignition).

Table 2. Mix proportions (wt.\%).

\begin{tabular}{|c|c|c|c|c|c|c|c|c|c|}
\hline Sample ID & CG & GFBS & SAC & HCSA & UEA & $\mathrm{Na}_{2} \mathrm{O}$ & Activator Modulus & W/B Ratio & B/S Ratio \\
\hline AACGS & 40 & 60 & 1 & 1 & 1 & \multirow{10}{*}{8} & \multirow{10}{*}{1.6} & \multirow{10}{*}{0.4} & \multirow{10}{*}{0.5} \\
\hline AACGS-3SAC & 38.5 & 58.5 & 3 & 1 & 1 & & & & \\
\hline AACGS-5SAC & 37.5 & 57.5 & 5 & 1 & 1 & & & & \\
\hline AACGS-7SAC & 36.5 & 56.5 & 7 & 1 & 1 & & & & \\
\hline AACGS-3HCSA & 38.5 & 58.5 & 1 & 3 & 1 & & & & \\
\hline AACGS-5HCSA & 37.5 & 57.5 & 1 & 5 & 1 & & & & \\
\hline AACGS-7HCSA & 36.5 & 56.5 & 1 & 7 & 1 & & & & \\
\hline AACGS-3UEA & 38.5 & 58.5 & 1 & 1 & 3 & & & & \\
\hline AACGS-5UEA & 37.5 & 57.5 & 1 & 1 & 5 & & & & \\
\hline AACGS-7UEA & 36.5 & 56.5 & 1 & 1 & 7 & & & & \\
\hline
\end{tabular}

\subsection{Testing Methods}

The compressive strengths were tested in accordance with China standard GB/T 176711999. The reported result was the average value of three tests for each sample. Drying shrinkage was evaluated according to the China standard GB/T 29417-2012. Samples with the size of $25 \times 25 \times 280 \mathrm{~mm}$ were prepared, and cured in the curing room with $\mathrm{RH}$ (relative humidity) of $60 \pm 5 \%$ and temperature of $20 \pm 2{ }^{\circ} \mathrm{C}$ after demolded. The reaction heat release was measured by using a SETARAM AIR C80 with isothermal calorimeter at $25{ }^{\circ} \mathrm{C}$. Thermogravimetry (TG) analysis was conducted by using a NETZSCH STA $449 \mathrm{C}$ thermogravimetric analyzer. The temperature was increased from 40 to $1000{ }^{\circ} \mathrm{C}$, and the heating rate was $10^{\circ} \mathrm{C} / \mathrm{min}$ in nitrogen atmosphere. X-ray diffraction (XRD) was performed by using a Sharp Shadow diffractometer, with scanning range of 5 to $70^{\circ}\left(2 \theta^{\circ}\right)$, a resolution of $0.02^{\circ} /$ step and a scanning speed of $2^{\circ} / \mathrm{min}$. The BET measurement was conducted by applying a micromeritic Tristar II 3020 multichannel specific surface area and aperture analyzer with pore size range from 2.0 to $300 \mathrm{~nm}$.

\section{Results and Discussion}

\subsection{Reaction Heat Release}

Figure 1 shows the effects of SAC, HCSA and UEA on reaction heat flow of alkali activated coal gangue-slag composites during the first $72 \mathrm{~h}$. Two typical heat release peaks can be observed; one, which occurs within the first few minutes, refers to the initial wetting and dissolution of slag and coal gangue particles in contact with water, while the second peak represents the formation of reacted gels and crystalline phases, generally including C-(A)-S-H, N-(A)-S-H and hydrotalcite [34,35]. During the stage of initial wetting, mixtures with an additive dosage of $7 \%$ exhibits a relatively lower heat release peak, and the addition of $3 \%$ expansive agent presents limited effect on this characteristic peak, except the one with 
$3 \%$ HCSA. It should be noted that the induction period in alkali activated materials is much shorter than that in Portland cement systems. During the acceleration stage, the addition of $S A C$ results in a reduced peak intensity with a delayed peak value. This can be attributed to the relatively high $\mathrm{Al}_{2} \mathrm{O}_{3}$ content in $\mathrm{SAC}$, which as well presents a higher reactivity than the $\mathrm{Al}_{2} \mathrm{O}_{3}$ in calcined coal gangue, resulting in a delayed dissolution of aluminates from calcined coal gangue [36]. In mixtures with HCSA and UEA addition, similar influences on the reaction process can be observed: with a relatively low replacement of $3 \%$, both HCSA and UEA promote the reaction process with increased peak intensity and earlier exothermic peak location, the effect of HCSA is more significant than UEA on this issue; while when a higher replacing level of $7 \%$ is applied, a delayed reaction process results. It is suggested that the acceleration effect of HCSA and UEA is assigned to their relatively high $\mathrm{MgO}$ content (as shown in Table 1), and the inhibited reaction process at high dosage is related to the rapidly dissolved calcium ions from additives at the early stage, which inhibits the dissolution of original slag to some extent [37].

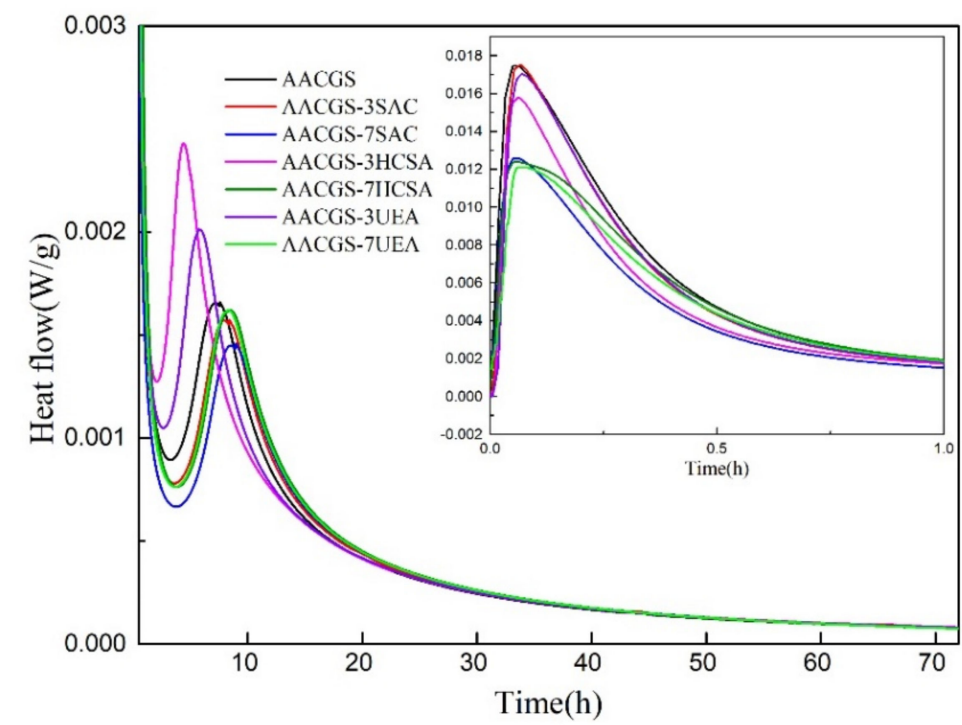

Figure 1. Influence of mineral admixture on reaction heat release.

\subsection{Drying Shrinkage}

The drying shrinkage of all mixtures up to 28 days is presented in Figure 2. The reference sample without any expansive additive shows a gradual increased shrinkage up to $9.311 \times 10^{-4}$ at day 28. It can be seen from Figure 2 a that the incorporation of sulphoaluminate cement (SAC) exhibits a positive effect on reducing the drying shrinkage of alkali activated coal gangue-slag composite. When 3\% SAC is added, the drying shrinkage is reduced by around $10 \%$ at day 28 compared to the reference sample, the increment of SAC content up to $5 \%$ results in a more obvious reduction of drying shrinkage by $27.3 \%$, but a higher dosage of $7 \%$ SAC does not result in further reduced drying shrinkage, with a reduction rate of about $20.1 \%$. A more significant effect on reducing the drying shrinkage can be observed in samples with an HCSA addition, as shown in Figure $2 \mathrm{~b}$. As the HCSA content increases from $3 \%$ to $5 \%$, the 28 day dry shrinkage is $4.476 \times 10^{-4}$ and $3.476 \times 10^{-4}$, respectively, which is $51.9 \%$ and $62.8 \%$, respectively, lower than the reference mix. When the HCSA dosage increases to $7 \%$, the shrinkage value gradually decreases after $1 \mathrm{~d}$ of curing, and the shrinkage rate becomes negative after around 14 days, indicating that this dosage would result in a mixture with slight expansion. The effect of UEA on drying shrinkage is depicted in Figure 2c; incorporating 3\% UEA led to a shrinkage reduction of $38.4 \%$, which is slightly less effective compared to HCSA with the same dosage. However, further increased UEA content, up to 5\% and 7\%, result in a shrinkage value of $-68.133 \times 10^{-4}$ and $-138.112 \times 10^{-4}$, respectively, showing dramatical expansion. Obvious cracks from the macro level are also found from the corresponding 
samples. It should be mentioned that Figure 2c presents the shrinkage value in a different magnitude compared to Figure 2a,b, due to the significant expansion behavior with high UEA dosages. Applying expansive additives can be an effective approach in reducing the drying shrinkage of alkali activated coal gangue-slag mixtures, and the shrinkage behavior seem to be quite sensitive to the additive's type and dosage.

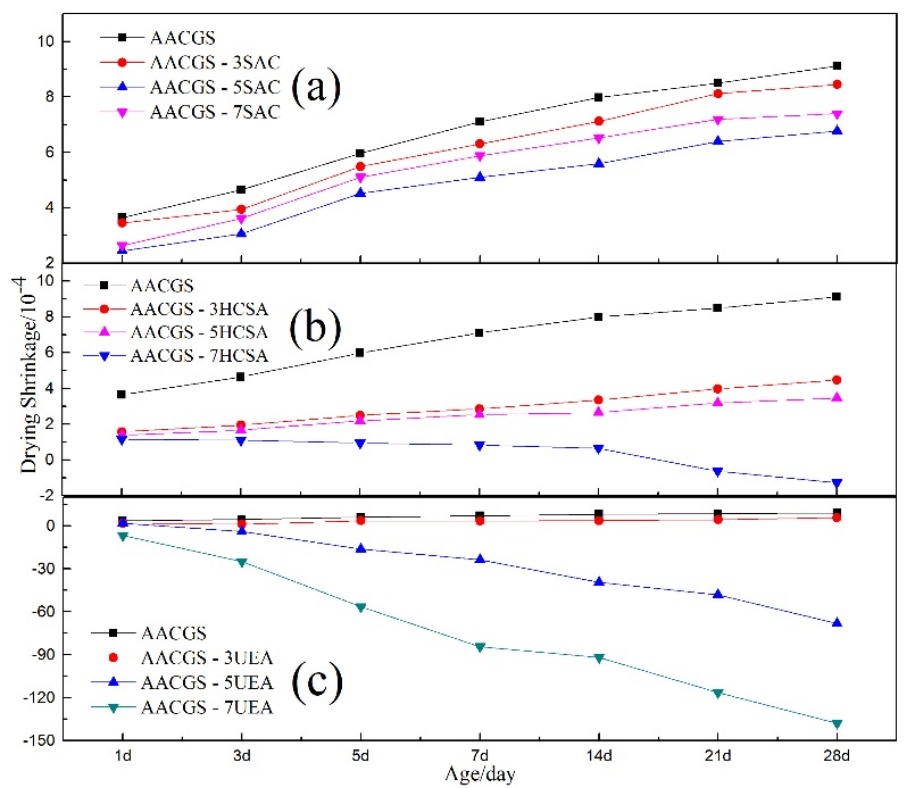

Figure 2. Influence of additives on the drying shrinkage of AACGS. (a) Drying shrinkage of AACGS with SAC, (b) drying shrinkage of AACGS with HCSA and (c) drying shrinkage of AACGS with UEA.

\subsection{Thermogravimetry Analysis}

Figure 3 presents the DTG curves of alkali activated coal gangue-slag composite with different expansive additives. The endothermic peak within the temperature range of 40-200 ${ }^{\circ} \mathrm{C}$ is related to the dehydration of free and bound water in the matrix and the reacted gels $[38,39]$. In addition to the mass loss due to the dehydration of water, three characteristic endothermic peaks can be observed: (1) The one between $200{ }^{\circ} \mathrm{C}$ and $400{ }^{\circ} \mathrm{C}$, mainly representing the decomposition of hydrotalcite phases. This peak is only obvious in samples with SAC addition, possibly because of the significant higher aluminate contents among three expansive additives, resulting in the formation of additional hydrotalcite within the reaction products. (2) The endothermic peak within $400-600{ }^{\circ} \mathrm{C}$, representing the decomposition of $\mathrm{Ca}(\mathrm{OH})_{2}$. This peak is more obvious in the mixtures containing HCSA and UEA; this can be attributed to their relatively high calcium content, as can be seem from Table 1. (3) The endothermic peak in the temperature range of $600-800{ }^{\circ} \mathrm{C}$. This is due mainly to the decomposition of the carbonate phase [40]. Similar to the presence of $\mathrm{Ca}(\mathrm{OH})_{2}$, this peak seems to be related with the calcium content in the additives, namely the higher content of calcium from the raw materials, the higher the $\mathrm{Ca}(\mathrm{OH})_{2}$ and $\mathrm{CaCO}_{3}$ contents within the reaction products. Table 3 lists the mass losses of each characteristic endothermic peak. The incorporation of expansive additives leads to increased free/bound water content; the water content is increased by $13.7-54.8 \%$ in general. All additives present similar modification effect on this issue at the dosage of $3 \%$, while the influence of HCSA and UEA is more significant at a higher replacement of $7 \%$. The obviously higher mass loss of mixtures with 7\% HCSA and UEA is well related to their remarkably increased shrinkage as shown in Figure 2, indicating that the increment of calcium containing phases may be the reason of expansion or shrinkage reduction in UCSA and UEA incorporated mixes. HCSA and UEA addition results in an increase of $\mathrm{Ca}(\mathrm{OH})_{2}$ and $\mathrm{CaCO}_{3}$ contents, while incorporation of SAC mainly introduces a hydrotalcite phase, indicating their different shrinkage reducing mechanisms in alkali activated binding systems. 


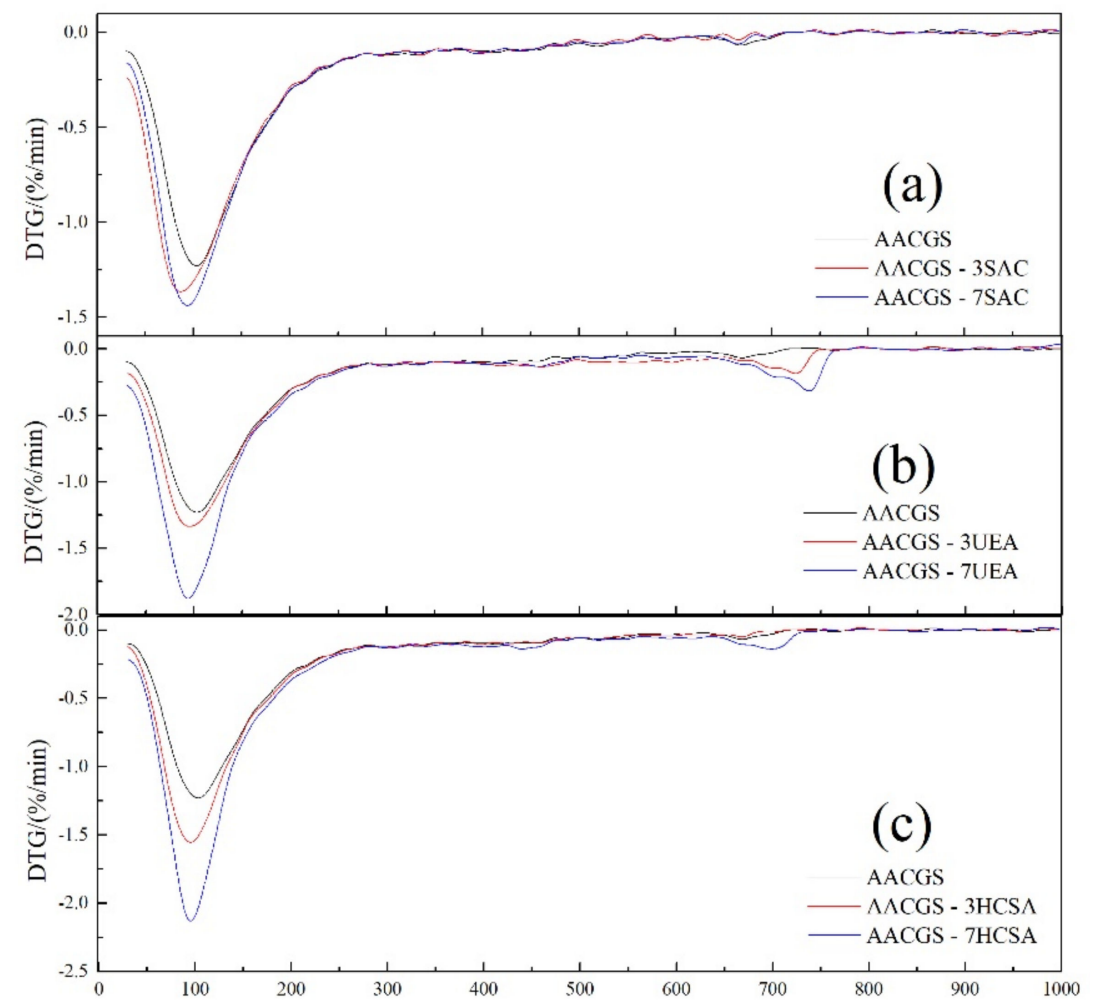

Figure 3. DTG curves of AACGS mixtures after $28 \mathrm{~d}$ of curing. (a) DTG diagram of AACGS with SAC, (b) DTG diagram of AACGS with UEA and (c) DTG diagram of AACGS with HCSA.

Table 3. Weight loss between $40{ }^{\circ} \mathrm{C}$ and $1000{ }^{\circ} \mathrm{C}$ determined by TG.

\begin{tabular}{ccccc}
\hline \multirow{2}{*}{ Mix } & \multicolumn{4}{c}{ Mass Loss $\mathbf{( \% )}$} \\
\cline { 2 - 5 } & $\begin{array}{c}\mathbf{H}_{\mathbf{2}} \mathbf{O} \\
\left(\mathbf{4 0 - 2 0 0}{ }^{\circ} \mathbf{C}\right)\end{array}$ & $\begin{array}{c}\text { Hydrotalcite } \\
\left(\mathbf{2 0 0 - 4 0 0}{ }^{\circ} \mathbf{C}\right)\end{array}$ & $\begin{array}{c}\mathbf{C a}(\mathbf{O H})_{\mathbf{2}} \\
\left(\mathbf{4 0 0 - 6 0 0}{ }^{\circ} \mathbf{C}\right)\end{array}$ & $\begin{array}{c}\mathbf{C a C O}_{3} \\
\left(\mathbf{6 0 0 - 8 0 0}{ }^{\circ} \mathbf{C}\right)\end{array}$ \\
\hline AACGS & $12.01 \%$ & $3.08 \%$ & $3.29 \%$ & $1.02 \%$ \\
AACGS-3SAC & $14.09 \%$ & $3.19 \%$ & $3.11 \%$ & $0.79 \%$ \\
AACGS-7SAC & $14.48 \%$ & $3.13 \%$ & $2.80 \%$ & $0.65 \%$ \\
AACGS-3HCSA & $14.65 \%$ & $3.35 \%$ & $3.17 \%$ & $0.90 \%$ \\
AACGS-7HCSA & $18.59 \%$ & $3.83 \%$ & $3.97 \%$ & $3.19 \%$ \\
AACGS-3UEA & $13.66 \%$ & $3.26 \%$ & $5.19 \%$ & $4.18 \%$ \\
AACGS-7UEA & $17.66 \%$ & $3.66 \%$ & $4.32 \%$ & $6.78 \%$ \\
\hline
\end{tabular}

\subsection{X-ray Diffraction Analysis}

The XRD patterns of alkali activated coal gangue-slag composites after 28 days of curing are presented in Figure 4. The identified crystalline phases of the reference sample include quartz, potassium mica and gismondine, a hump peak around $27-35^{\circ}$ is assigned to the C-(A)-S-H and N-A-S-H type gels, probably with a certain amount of calcite $[41,42]$. All mixes share very similar peak intensity of quartz, potassium mica and gismondine, revealing that those phases are more likely from the binding materials of coal gangue and slag, rather than from the expansive additives. With the increase of expansive additive content, the peak intensity of calcite increases correspondingly, which is well related with the results from thermal analysis. Because of the overlapped peaks of calcite and hydrated gels, it is difficult to observe the effect of additives on the crystallinity of reacted gels. It should be mentioned that in samples with SAC addition, the hydrotalcite phases that are identified from the thermal analysis are not observed from the XRD analysis; this is because the hydrotalcite is usually poorly crystallized in alkali activated binding systems. Moreover, the portlandite that is observed from HCSA and UEA incorporated mixes, is also not found from the XRD patterns, probably due to its relatively low contents and 
poor crystalline degree. It is well known that those expansive additives usually modify the phase composition of Portland cement system by introducing crystalline phases like ettringite, portlandite and magnesium hydroxide $[43,44]$, therefore it can be indicated from the XRD analysis that their shrinkage reducing mechanisms are different in alkali activated binding systems.

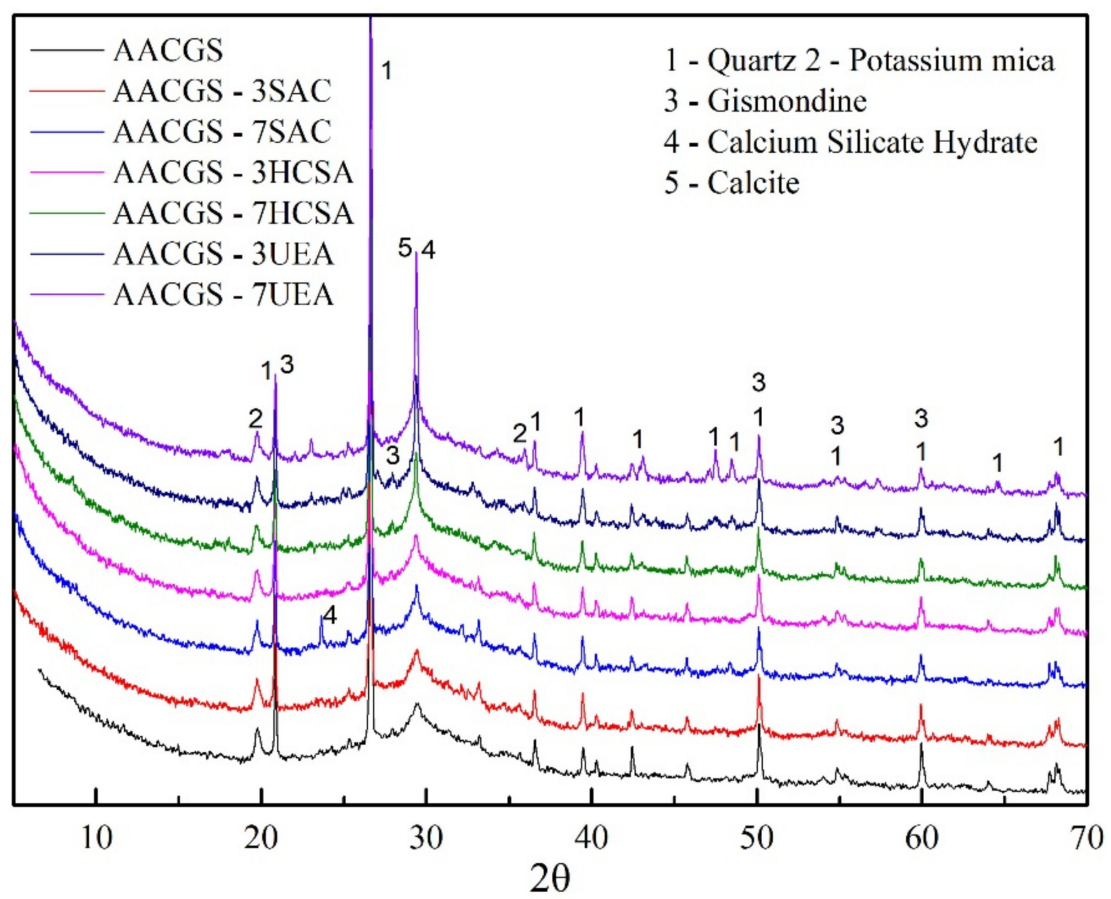

Figure 4. XRD pattern of AACGS mixture with mineral admixture in $28 \mathrm{~d}$.

\subsection{Brunner-Emmet-Teller (BET) Analysis}

The influence of SAC, HCSA and UEA on the pore characters of alkali activated coal gangue-slag composite is analyzed by BET measurement. Table 4 lists the specific surface area and average pore size of mixtures with $3 \%$ and $7 \%$ additive replacements. As shown in the table, the specific surface area of reference mixes is $33.40 \mathrm{~m}^{2} / \mathrm{g}$, and the addition of additives results in an obvious increased specific surface area in general. SAC replacement by $3 \%$ and $7 \%$ increases the specific surface area of hardened matrix by $8.9 \%$ and $9.5 \%$, respectively, indicating a remarkable influence of SAC on pore structure, while a limited effect is shown when a further higher dosage of SAC is applied. Similar with SAC, an increase of specific surface area by $5.8 \%$ and $5.9 \%$ is shown in mixtures with HCSA addition of $3 \%$ and $7 \%$, respectively. As for the effect of UEA, a more significant change in specific surface area by $43.9 \%$ and $84.6 \%$ is observed. In addition, the calculated average pore size of the reference mixture is $7.54 \mathrm{~nm}$, which is much lower than the commonly reported values of Portland cement based binders [25]. Adding expansive additives as binder replacements enlarges the average pore size in general. For a fixed additive replacement of $7 \%$, the incorporation of SAC, HCSA and UEA increases the average pore size by $7.2 \%, 8.2 \%$ and $17.4 \%$, respectively. Combined with the results shown in Figure 2, it can be seen that the shifts in drying shrinkage are closely related with their changes in pore characteristics. The relations between drying shrinkage, specific surface area and average pore size of alkali activated coal gangue-slag composite are presented in Figure 5. This figure reveals that the larger the average pore size is, the more obvious is the inhibition effect on drying shrinkage. This is because the pore size distribution is an important factor that controls the capillary pressure. During the curing process, the free water in the matrix gradually evaporates and results in pore tensile stress. By adding expansion additives, the drying shrinkage is then inhibited due to the increased pore sizes and therefore the reduced pore stress. 
Table 4. Average pore size of AACGS mortar (\%).

\begin{tabular}{ccc}
\hline Group & Specific Surface Area $\left(\mathbf{m}^{\mathbf{2}} \mathbf{g}\right)$ & Average Pore Size $(\mathbf{n m})$ \\
\hline AACGS & 33.40 & 7.54 \\
AACGS-3SAC & 36.39 & 8.04 \\
AACGS-7SAC & 36.59 & 8.08 \\
AACGS-3HCSA & 35.35 & 8.11 \\
AACGS-7HCSA & 35.38 & 8.16 \\
AACGS-3UEA & 48.06 & 8.15 \\
AACGS-7UEA & 61.67 & 8.85 \\
\hline
\end{tabular}

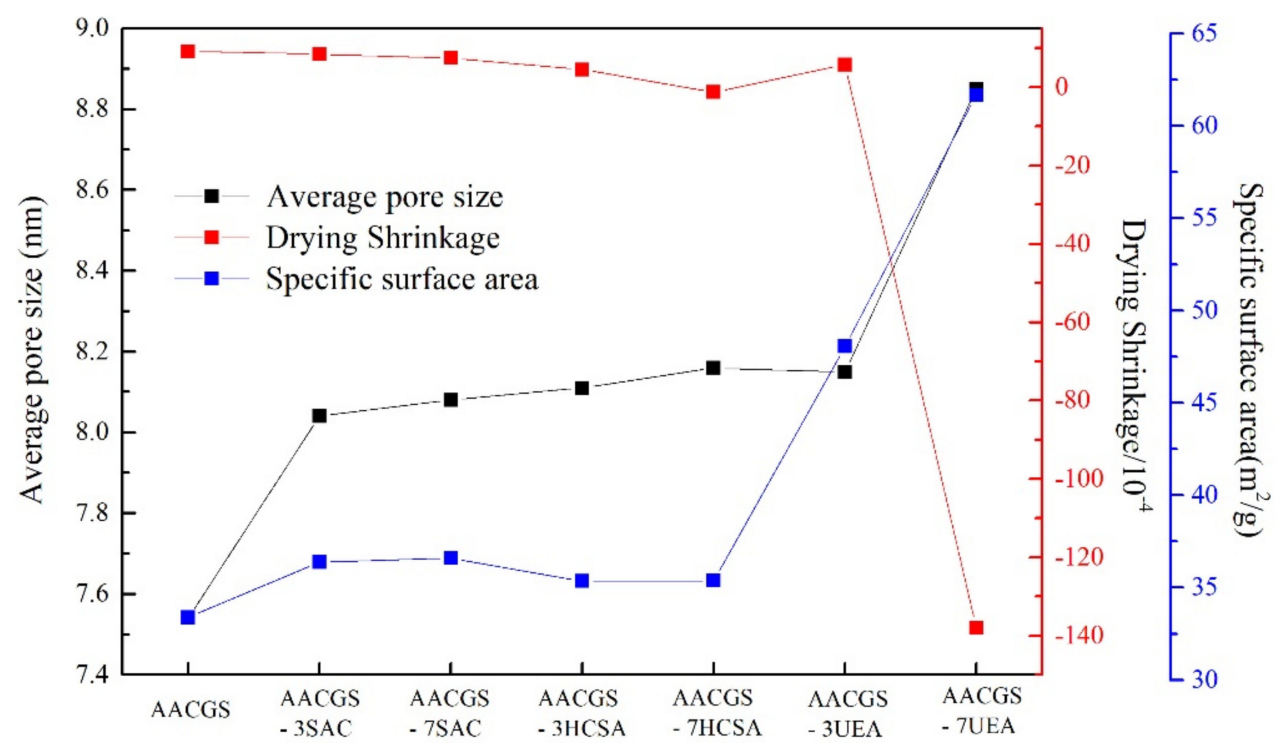

Figure 5. Relations between drying shrinkage and pore characteristics.

\subsection{Compressive Strength}

Table 5 shows the influence of different contents of SAC, HCSA and UEA on the compressive strength of alkali activated coal gangue-slag composites. The reference sample shows a $3 \mathrm{~d}$ and $28 \mathrm{~d}$ compressive strength of $39.4 \mathrm{MPa}$ and $51.7 \mathrm{MPa}$, respectively, similar to the grade 42.5 Portland cement. The addition of SAC within the dosage of $3 \%$ and $7 \%$ improves the compressive strength in general, and the optimum dosage is shown in mixes with $5 \%$ SAC, reaching the highest compressive strength of $63.1 \mathrm{MPa}$ after $28 \mathrm{~d}$ of curing. Adding HCSA with the dosage of $3 \%$ reduces the compressive strength by $8.1 \%$ at $3 \mathrm{~d}$ and $11.2 \%$ at $28 \mathrm{~d}$, but further higher replacement levels result in a dramatical decrease of compressive strength by up to $77.6 \%$ at $28 \mathrm{~d}$. The effect of UEA is similar to that of HCSA, but with a more obvious negative influence on strength. The remarkable strength reduction can be attributed to the expansion of the matrix, as shown in the drying shrinkage results. One character of the alkali activated binding system is its fast chemical reaction and gel formation at an early stage, and the formation speed of expansive components in HCSA and UEA incorporated mixtures may not be as fast as the reacted gels, so the growth of expansive phases at later stage destroy the already established matrix, resulting in excessive expansion and strength reduction; as can be seen the strength reduction of HCSA and UEA added samples is more obvious at later curing ages. Concerning the chemical composition of the three applied additives, the one with higher aluminate, and lower calcium and magnesium contents may present less negative effect on compressive strength. Thus in terms of the mechanical properties, it can be concluded that SAC presents a good compatibility to the alkali activated binding systems, and this binding system is very sensitive to the type and dosage of expansive additives. 
Table 5. Effect of expansive additives on compressive strength.

\begin{tabular}{|c|c|c|c|}
\hline \multirow{2}{*}{ Group } & \multicolumn{3}{|c|}{ Compressive Strength (MPa) } \\
\hline & $3 \mathrm{~d} / \mathrm{MPa}$ & $7 \mathrm{~d} / \mathrm{MPa}$ & $28 \mathrm{~d} / \mathrm{MPa}$ \\
\hline AACGS & 39.4 & 42.3 & 51.7 \\
\hline AACGS-3SAC & 44.4 & 48.2 & 56.3 \\
\hline AACGS-5SAC & 43.9 & 49.4 & 63.1 \\
\hline AACGS-7SAC & 42.8 & 46.5 & 60.6 \\
\hline AACGS-3HCSA & 36.2 & 37.3 & 45.9 \\
\hline AACGS-5HCSA & 39.8 & 21.8 & 16.6 \\
\hline AACGS-7HCSA & 24.7 & 15.6 & 11.6 \\
\hline AACGS-3UEA & 32.3 & 43.6 & 20.6 \\
\hline AACGS-5UEA & 29.1 & 36.5 & 9.3 \\
\hline AACGS-7UEA & 25.2 & 21.8 & 6.1 \\
\hline
\end{tabular}

\section{Conclusions}

In this study, three typical shrinkage reducing additives for Portland cement systems are used in alkali activated coal gangue-slag composites to evaluate their suitability in reducing drying shrinkage. The effect of SAC, HCSA and UEA on early stage reaction, shrinkage behavior, phase composition, pore characteristics, and mechanical properties are discussed. The following conclusions can be drawn based on the results:

1. In alkali activated binding system, the addition of SAC inhibits the early stage reaction to some extent. Incorporating HCSA and UEA promotes the reaction with a relatively low dosage of $3 \%$, while an opposite effect is shown with a higher replacement of $7 \%$.

2. All types of applied additives are able to mitigate the drying shrinkage of alkali activated coal gangue-slag composite, but excessive dosage of HCSA and UEA would result in expansion. The pore characteristics of the hardened matrix are well related with their shrinkage behavior.

3. Addition of SAC brings hydrotalcite phases within the reaction products, while HCSA and UEA addition mainly introduces $\mathrm{CaCO}_{3}$ and $\mathrm{Ca}(\mathrm{OH})_{2}$. Additionally formed phases are not observed from the XRD analysis due to their relatively low dosage and poor crystalline nature under the condition of alkali activation.

4. Applying SAC benefits the compressive strength in general, and an optimum dosage around $5 \%$ is suggested. The compressive strength is very sensitive to HCSA and UEA dosage; higher replacements would result in dramatic strength reduction due to expansion.

Author Contributions: Methodology, X.G. and C.L. writing-original draft preparation, C.L. and X.G.; writing-review and editing, X.G. and C.L.; supervision, X.G. and R.Y.; project administration, Z.S. All authors have read and agreed to the published version of the manuscript.

Funding: This work was supported by Sanya Science and Education Innovation Park of Wuhan University of Technology (Project No. 2020KF0008), and the open research project of Advanced Engineering Technology Research Institute of Wuhan University of technology in Zhongshan city (WUT202004).

Institutional Review Board Statement: Not applicable.

Informed Consent Statement: Not applicable.

Data Availability Statement: The data used to support the findings of this study are available from the corresponding author upon request.

Conflicts of Interest: The authors declare no conflict of interest. 


\section{References}

1. Li, Y.J.; Yan, X.P. Experimental study on the durability of the concrete with coal gangue aggregate. J. China Coal Soc. 2013, 38, 1215-1219.

2. Wang, X.; Zhong, N.; Han, X. Impacts of coal gangue stockpiling on polycyclic aromatic hydrocarbons pollution in soil environment. Huanjing Kexue Xuebao/Acta Sci. Circumstantiae 2013, 33, 3092-3100.

3. Lü, Q.; Dong, X.; Zhu, Z.; Dong, Y. Environment-oriented low-cost porous mullite ceramic membrane supports fabricated from coal gangue and bauxite. J. Hazard. Mater. 2014, 273, 136-145. [CrossRef]

4. Chuncai, Z.; Guijian, L.; Dun, W.; Fang, T.; Wang, R.; Xiang, F. Mobility behavior and environmental implications of trace elements associated with coal gangue: A case study at the Huainan Coalfield in China. Chemosphere 2014, 95, 193-199. [CrossRef] [PubMed]

5. Fabiańska, M.J.; Ciesielczuk, J.; Kruszewski, Ł.; Misz-Kennan, M.; Blake, D.R.; Stracher, G.; Moszumańska, I. Gaseous compounds and efflorescences generated in self-heating coal-waste dumps-A case study from the Upper and Lower Silesian Coal Basins (Poland). Int. J. Coal Geol. 2013, 116, 247-261. [CrossRef]

6. Ribeiro, J.; da Silva, E.F.; Flores, D. Burning of coal waste piles from Douro Coalfield (Portugal): Petrological, geochemical and mineralogical characterization. Int. J. Coal Geol. 2010, 81, 359-372. [CrossRef]

7. Aiqin, L.; Shaoping, K.; Hua, D. The discussion of comprehensive utilization of coal gangue. China Resour. Compr. Util. 2004, 2, 11-14.

8. Haibin, L.; Zhenling, L. Recycling utilization patterns of coal mining waste in China. Resour. Conserv. Recycl. 2010, 54, 1331-1340. [CrossRef]

9. Li, D.; Song, X.; Gong, C.; Pan, Z. Research on cementitious behavior and mechanism of pozzolanic cement with coal gangue. Cem. Concr. Res. 2006, 36, 1752-1759. [CrossRef]

10. Song, Q.; Yu, R.; Shui, Z.; Wang, Y. Physical and chemical coupling effect of metakaolin induced chloride trapping capacity variation for Ultra High Performance Fibre Reinforced Concrete (UHPFRC). Constr. Build. Mater. 2019, 223, 765-774. [CrossRef]

11. Wang, Y.; Shui, Z.; Gao, X.; Huang, Y.; Yu, R.; Ling, G. Chloride binding behaviors of metakaolin-lime hydrated blends: Influence of gypsum and atmospheric carbonation. Constr. Build. Mater. 2019, 201, 380-390. [CrossRef]

12. Zhou, S.; Dong, J.; Yu, L.; Xu, J.; Jiao, K.; Wang, Y. Effect of Activated Coal Gangue in North China on the Compressive Strength and Hydration Process of Cement. J. Mater. Civ. Eng. 2019, 31, 04019022. [CrossRef]

13. Duxson, P.; Fernández-Jiménez, A.; Provis, J.L.; Lukey, C.; Palomo, A.; Deventer, S. Geopolymer technology: The current state of the art. J. Mater. Sci. 2007, 42, 2917-2933. [CrossRef]

14. Wang, S.D.; Scrivener, K.L. Hydration products of alkali activated slag cement. Cem. Concr. Res. 1995, 25, 561-571. [CrossRef]

15. Granizo, M.L.; Alonso, S.; Blanco-Varela, M.T.; Palomo, A. Alkaline activation of metakaolin: Effect of calcium hydroxide in the products of reaction. J. Am. Ceram. Soc. 2002, 85, 225-231. [CrossRef]

16. Li, C.; Sun, H.; Li, L. A review: The comparison between alkali-activated slag ( $\mathrm{Si}+\mathrm{Ca})$ and metakaolin $(\mathrm{Si}+\mathrm{Al})$ cements. Cem . Concr. Res. 2010, 40, 1341-1349. [CrossRef]

17. Allahverdi, A.; Skvara, F. Sulfuric acid attack on hardened paste of geopolymer cements-Part 1. Mechanism of corrosion at relatively high concentrations. Ceram. Silik. 2005, 49, 225.

18. Bakharev, T. Durability of geopolymer materials in sodium and magnesium sulfate solutions. Cem. Concr. Res. 2005, 35, 1233-1246. [CrossRef]

19. Lee, N.K.; Jang, J.G.; Lee, H.K. Shrinkage characteristics of alkali-activated fly ash/slag paste and mortar at early ages. Cem. Concr. Compos. 2014, 53, 239-248. [CrossRef]

20. Mastali, M.; Kinnunen, P.; Dalvand, A.; Firouz, M.; Illikainen, M. Drying shrinkage in alkali-activated binders-a critical review. Constr. Build. Mater. 2018, 190, 533-550. [CrossRef]

21. Cartwright, C.; Rajabipour, F.; Radlińska, A. Shrinkage characteristics of alkali-activated slag cements. J. Mater. Civ. Eng. 2014, 27, B4014007. [CrossRef]

22. Thomas, R.J.; Lezama, D.; Peethamparan, S. On drying shrinkage in alkali-activated concrete: Improving dimensional stability by aging or heat-curing. Cem. Concr. Res. 2017, 91, 13-23. [CrossRef]

23. Kheradmand, M.; Abdollahnejad, Z.; Pacheco-Torgal, F. Shrinkage performance of fly ash alkali-activated cement based binder mortars. KSCE J. Civ. Eng. 2018, 22, 1854-1864. [CrossRef]

24. Ma, H.Q.; Chen, H.Y.; Zhu, H.G.; Shi, Y.Y.; Ni, Y.D.; Huo, Q.J.; Hang, Z.T. Study on the drying shrinkage of alkali-activated coal gangue-slag mortar and its mechanisms. Constr. Build. Mater. 2019, 225, 204-213.

25. Collins, F.; Sanjayan, J.G. Effect of pore size distribution on drying shrinking of alkali-activated slag concrete. Cem. Concr. Res. 2000, 30, 1401-1406. [CrossRef]

26. Huang, G.; Ji, Y.; Li, J.; Hou, Z.; Dong, Z. Improving strength of calcinated coal gangue geopolymer mortars via increasing calcium content. Constr. Build. Mater. 2018, 166, 760-768. [CrossRef]

27. Bakharev, T.; Sanjayan, J.G.; Cheng, Y.B. Effect of admixtures on properties of alkali-activated slag concrete. Cem. Concr. Res. 2000, 30, 1367-1374. [CrossRef]

28. Yip, C.K.; Provis, J.L.; Lukey, G.C.; Deventer, J. Carbonate mineral addition to metakaolin-based geopolymers. Cem. Concr. Compos. 2008, 30, 979-985. [CrossRef]

29. Güneyisi, E.; Gesoğlu, M.; Mermerdaş, K. Improving strength, drying shrinkage, and pore structure of concrete using metakaolin. Mater. Struct. 2008, 41, 937-949. [CrossRef] 
30. Jin, F.; Al-Tabbaa, A. Strength and drying shrinkage of slag paste activated by sodium carbonate and reactive MgO. Constr. Build. Mater. 2015, 81, 58-65. [CrossRef]

31. Haha, M.B.; Lothenbach, B.; Le Saout, G.L.; Winnefeld, F. Influence of slag chemistry on the hydration of alkali-activated blast-furnace slag_Part I: Effect of MgO. Cem. Concr. Res. 2011, 41, 955-963. [CrossRef]

32. Yang, L.Y.; Jia, Z.J.; Zhang, Y.M.; Dai, J.G. Effects of nano- $\mathrm{TiO}_{2}$ on strength, shrinkage and microstructure of alkali activated slag pastes. Cem. Concr. Compos. 2015, 57, 1-7. [CrossRef]

33. Hanjitsuwan, S.; Injorhor, B.; Phoo-ngernkham, T.; Damrongwiriyanupap, N.; Li, L.Y.; Sukontasukkul, P.; Chindaprasirt, P. Drying shrinkage, strength and microstructure of alkali-activated high-calcium fly ash using FGD-gypsum and dolomite as expansive additive. Cem. Concr. Compos. 2020, 114, 103760. [CrossRef]

34. Shi, C.; Roy, D.; Krivenko, P. Alkali-Activated Cements and Concretes; CRC Press: Boca Raton, FL, USA, 2003.

35. Alonso, S.; Palomo, A. Calorimetric study of alkaline activation of calcium hydroxide-metakaolin solid mixtures. Cem. Concr. Res. 2001, 31, 25-30. [CrossRef]

36. Abdel-Gawwad, H.A.; Mohammed, M.S.; Alomayri, T. Single and dual effects of magnesia and alumina nano-particles on strength and drying shrinkage of alkali activated slag. Constr. Build. Mater. 2019, 228, 116827. [CrossRef]

37. Liska, M. Properties and Applications of Reactive Magnesia Cements in Porous Blocks; University of Cambridge: Cambridge, UK, 2010.

38. Abdel-Gawwad, H.A.; Heikal, M.; Mohammed, M.S.; El-Aleem, S.; Hassan, H.S.; Garcia, S.R.V.; Rashad, A.M. Evaluating the impact of nano-magnesium calcite waste on the performance of cement mortar in normal and sulfate-rich media. Constr. Build. Mater. 2019, 203, 392-400. [CrossRef]

39. Abdel-Gawwad, H.A.; Khalil, K.A. Application of thermal treatment on cement kiln dust and feldspar to create one-part geopolymer cement. Constr. Build. Mater. 2018, 187, 231-237. [CrossRef]

40. Abdel-Gawwad, H.A.; El-Enein, S.A.A.; Heikal, M.; El-Aleem, S.; Amer, A.A.; El-Kattan, I.M. Synergistic effects of curing conditions and magnesium oxide addition on the physico-mechanical properties and firing resistivity of Portland cement mortar. Constr. Build. Mater. 2018, 176, 676-689. [CrossRef]

41. Rashad, A.M. A comprehensive overview about the influence of different additives on the properties of alkali-activated slag-A guide for Civil Engineer. Constr. Build. Mater. 2013, 47, 29-55. [CrossRef]

42. Provis, J.L.; Palomo, A.; Shi, C. Advances in understanding alkali-activated materials. Cem. Concr. Res. 2015, 78, 110-125. [CrossRef]

43. Nie, L.L.; Sun, S.B.; Yao, X.D.; Tian, Y.L. Study on the properties of ordinary portland cement and fast hardening sulphoaluminate cement mortar. Concr. Cem. Prod. 2014, 3, 10-13.

44. Zhao, S.; Li, C.; Jia, F.; Wu, X.N. Study on self healing of shrinkage cracks in HCSA shrinkage compensating concrete. Expans. Agent Expans. Concrete 2017, 3, 1-4. 